\title{
Why Girl Students' Achieve English Presentation Learning Significantly Better in Shanghai University of Engineering Science (SUES)
}

\author{
Wen ZHU ${ }^{1}$ \& Zhixin $\mathrm{LIU}^{1}$ \\ ${ }^{1}$ School of Foreign Language, Shanghai University of Engineering Science, Shanghai, China \\ Correspondence: Wen Zhu, School of Foreign Language, Shanghai University of Engineering Science, Shanghai, \\ China. Tel: 0086-13524253396. E-mail: 21110003@sues.edu.cn
}

Received: April 16, 2017 Accepted: June 9, 2017 Online Published: June 12, 2017

doi: 10.5539/elt.v10n7p203ＵRL: http://doi.org/10.5539/elt.v10n7p203

\begin{abstract}
In non literature major dominated university, it is obviously noted that girl students' English (as the second language) presentation scores often higher than boy students in the same teaching environment and evaluation system. A 397 samples' survey has been studied from the aspects of after school activities and sleep schedule to discuss if any influences on the students' English learning motives and performance.
\end{abstract}

Keywords: Learning English as second language, English presentation, Chinese college students, non-literature majored, living pattern, video game and mobile phone playing, sports, sleep length, bed time

\section{Introduction}

Among all the mandatory courses in Shanghai University of Engineering Science (SUES), a science and engineering majors dominated university, English (as $2^{\text {nd }}$ language) presentation course is viewed as the relaxing one by students due to its lack of paperwork and heavy research job. Unlike other serious academic courses, high leveled score is easily achieved by demonstrating strong learning and presenting motives with basic English skills upon the course evaluation scale system. In SUES, Students are required to fulfill at least 2 credits per semester for 4 semesters. Therefore, students have enough time and attention to improve their presentation skills.

Even with the advantages mentioned above, the English presentation courses' overall score of boy students is always below satisfying level after 4 semesters learning. Interestingly, the majority of the students fail to pass this courses are almost boy students.

Numerous research studies have indicated that from physiological aspects, females tend to master foreign languages easier than males (Fan, 2010; Wang, 2015). This paper intends to discuss if the after school activities, sleep schedule in college life may influence the boys' motive in improving their English presentation ability, and why boy students and girl students' performances in English Presentation differ dramatically in the exactly same teaching system, with mastering very close amount of vocabularies.

Apart from students' academic study, playing video games or mobile phone ranks the top among various after school activities. It seriously influences students' academic performance in China (Shostya, 2015). Differing from other academic courses in SUES, English presentations course is not demanding in research. Even so, lack of self-motivations in interacting with others, nor in presenting their own ideas are demonstrated by most boy students. Not many studies have revealed if the video game would influence college students' English ( $2^{\text {nd }}$ language) presentation ability and motives as it does towards normal academic ones. Other basic factors of sleep schedule are included into consideration, which reported effecting academic performance. (Aabid et al., 2013). Factors of sleep length and go to bed time are also included in this study for the reason that they directly relate to video game and mobile phone playing.

In SUES, The brief presentation scale system is as below: It demands more about the presentation attitudes than the English vocabularies. 
Table 1. The assessment table for English $\left(2^{\text {nd }}\right.$ language $)$ presentation level 4 in SUES

\begin{tabular}{ll}
\hline Criterion & Weight \\
\hline attendance & $15 \%$ \\
deliver the presentation with confidence and certain fluency & $35 \%$ \\
(Strongly related with learning motives and activeness) & \\
The effectiveness; efficiency; logic of the presentation construction & $20 \%$ \\
The appropriate presentation manner, body language & $15 \%$ \\
The correctness of grammar, verbal, pronouncing & $15 \%$ \\
\hline
\end{tabular}

\section{Method}

\subsection{Participants}

A survey was carried at the end of the spring semester 2016 among 416 students randomly selected, finishing their $8^{\text {th }}$ English Presentation credit study, all $2^{\text {nd }}$-grade undergraduate students. Their majors diverse as:

1) Mechanical Engineering

2) Chemical Engineering

3) Civil Engineering

4) Aviation

5) Management

6) Material Engineering

7) Finance

8) Textile engineering

Questionnaires were given to them before the final examination.

The questionnaires were given through a 2 minutes one on one interview. To avoid mistakes, questions were clearly explained individually and students' answers were verified. Questions are:

1) When you usually get up in weekday?

2) When you usually shut down light and mobile phone to sleep?

3) Do you play interactive electronic devices, like PCs and mobile phones?

a) If yes, how long you play per day approximately?

b) During what time you play, before sleep? Daytime?

4) Do you exercise? How long approximately a day?

These data were collected in excel form. The $5^{\text {th }}$ column was generated for 'length of sleep time' by articulating from 'wake up time' and 'sleep time'. Correlation statistic tools were applied to find out the gradient how these video games and chatting tools influence their basic sleep time, living pattern, and consequentially effect their English presentation skills buildup.

The final examination scores (100 points weight) were added to the $6^{\text {th }}$ column.

All data was processed by minilab statistic tools.

After the data was processed, brief interviews were conducted for abnormal answers.

\section{Results}

379 valid students' valid data were finally collected: 102 girl students and 277 boy students. The other 19 students' answers were abandoned for the data input errors.

The final presentation scores differ significantly among boys and girls students as expected: 


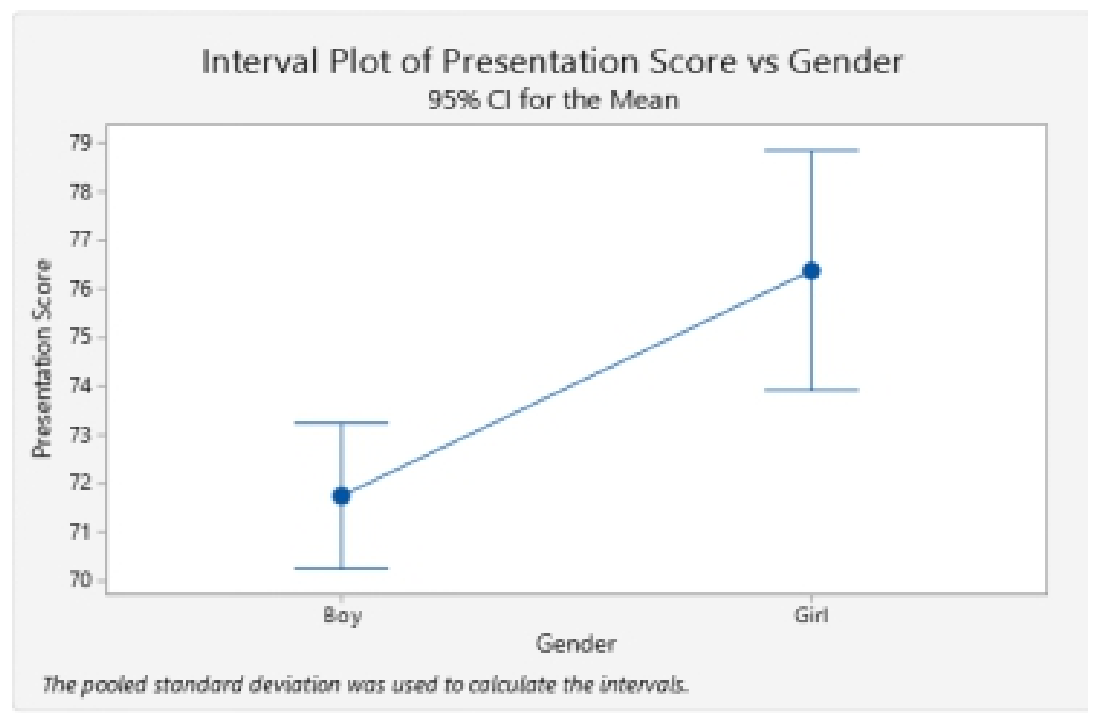

Figure 1. The ANOVA test for testing the significant difference between boy students' score and girl students' score

Girl students' score level is significantly higher than the boy students. Among the 13 students failed the examination, only 2 are girl students, consisting only $15 \%$, while among the A scored students, the number of girl students is 15 among 33 total for $46 \%$. Considering the total percentage of girl students among 397 is $26 \%$, it is evident that girl students' English presentation ability strongly surpassing boy students in SUES. What needs to be noted that girl students' vocabulary and reading scores are very close upon the assessment in SUES.

The sleep is the main component of the college students' lifestyle (Ali et al., 2013). The difference in sleep length between boy students and girl students is not significant upon the survey results. The p-value is 0.4018 . The mean value of sleep length of boy students is 7 hour 31 minutes; for girl students is slightly less: 7 hours 25 minutes. Though some extreme cases do occur, like 11 hours for sleep for 2 boy student and 10 hours sleep for 1 girl student, less than 4 hours sleep for 3 boy students. The majority of the students' sleep length is over7 hours, which meets the recommended adult sleep time standard (JCSM, 2015).

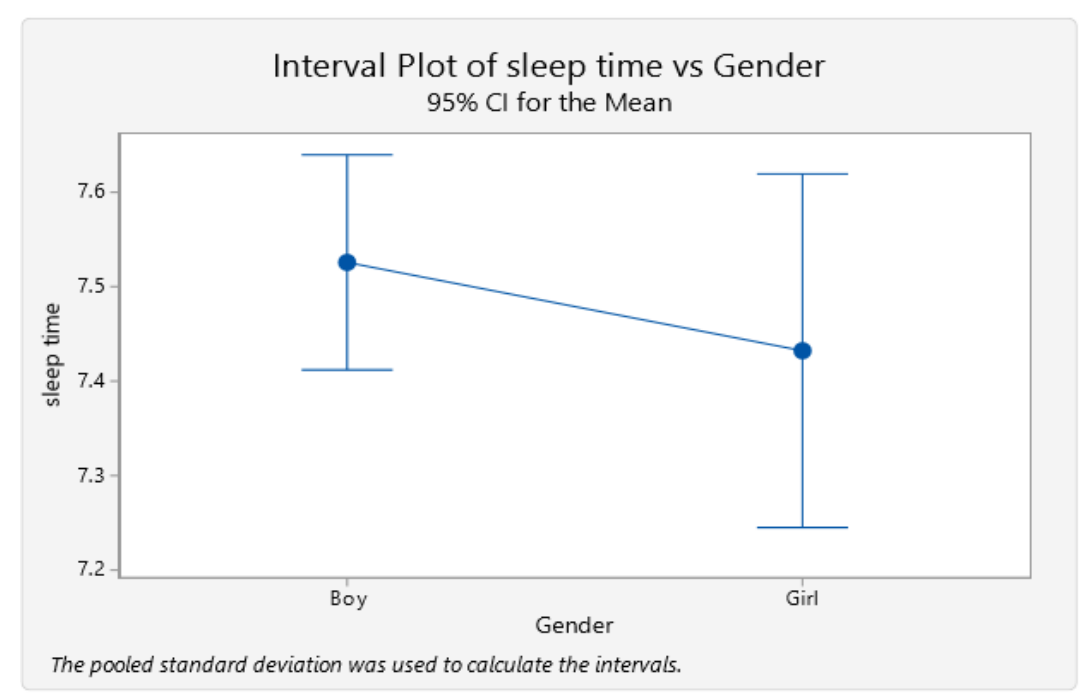

Figure 2. The comparison of sleep length of boy students and girl students

The result of the sports time reflects the significant difference of the time students spend daily on sports for boys and girls $(\mathrm{p}=0.073)$. Boy students are much active in physical sports in SUES. The mean of sports time boys 
spend daily is 55 minutes. The mean of girls is only 33 minutes. Among 55 students whose daily sports time exceeding 1 hour, only 8 are girls, around 14\%, comparing with the $26 \%$ of girl students in population, it does indicate the majority of girl students in SUES are far less active nor interested in physical sports.

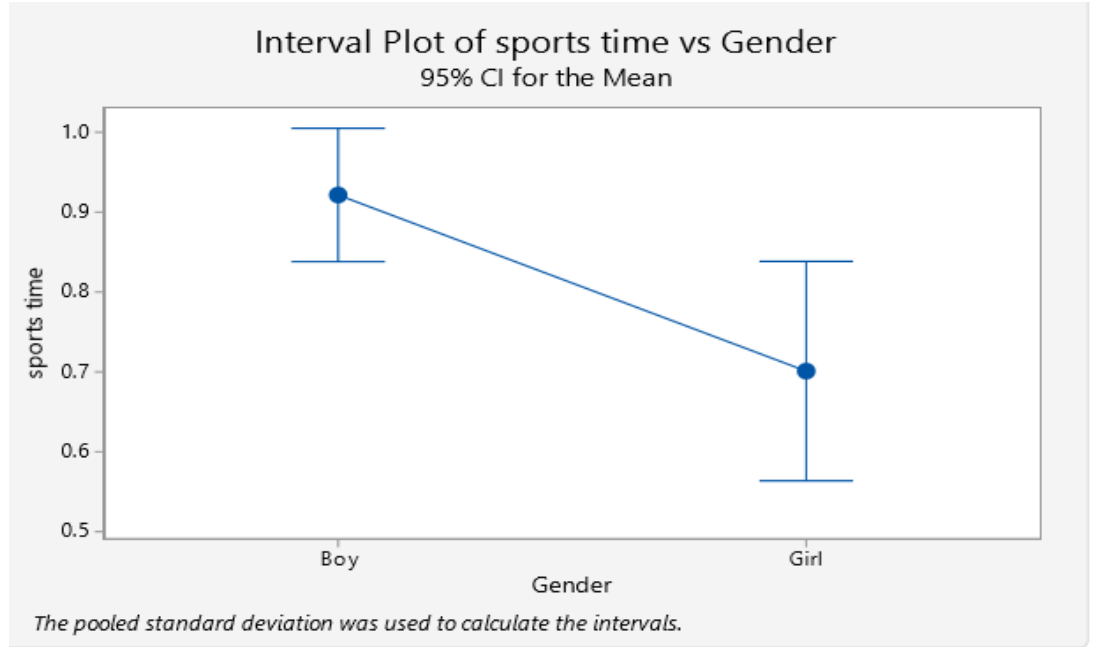

Figure 3. The comparison of daily sports time between girl students and boy students in SUES

When it comes to the video game time and mobile phone daily playing time, the difference between boy students and girl students is even more significant than the daily sports time $(\mathrm{p}=0.0038)$. The mean of the daily game time of boys is 2 hours 54 minutes with the $95 \%$ cl interval ranges $(2.6999,3.1008)$. The mean of girls is 2 hours 19 minutes with the $95 \% \mathrm{cl}$ interval ranges $(1.9987,2.6581)$. Only 2 girl students, $10 \%$ are counted in the 20 extreme case of playing video games exceed 8 hours a day. It is clear that boy students are much more addicted to playing interactive electronic devices than girl students.

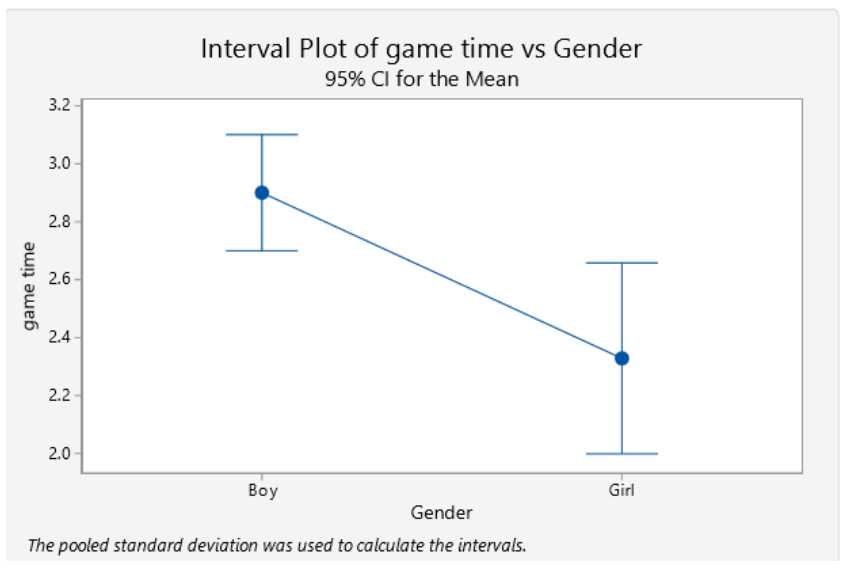

Figure 4. The ANOVA test and box bar of the daily video game and mobile phone playing time comparison between boy students and girl students 


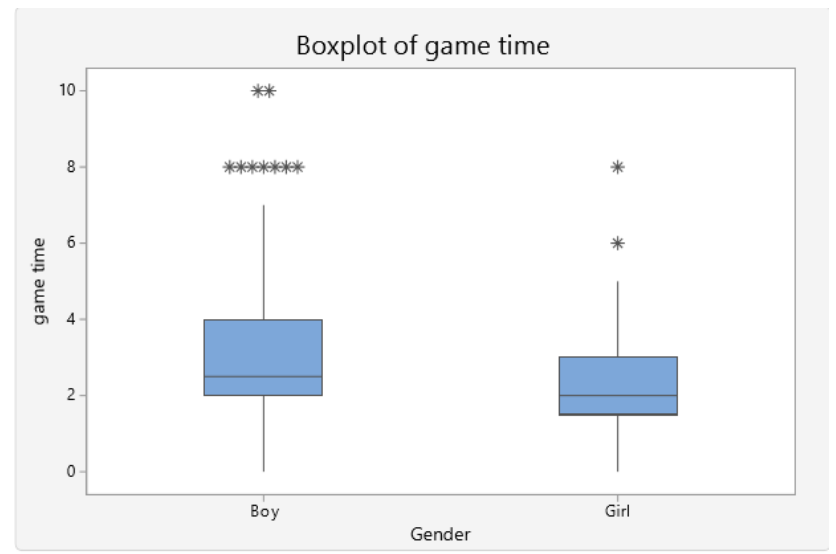

Figure 5. The boxplot of the comparison of the time spent on video games and mobile phones between boys and girls

Despite the much more additional time put into games and sports, the result of bedtime does not differ much from boy students and girl students $(\mathrm{p}=0.104)$. The mean bedtime for boys is $23: 58$ with $95 \% \mathrm{cl}$ interval $(23: 48$, 0:03). The mean bed time for girls is $23: 49$ with $95 \% \mathrm{cl}$ interval $(23: 40,23: 58) .7$ samples' bedtime is after 2:00 AM, only 1 girl student included.

19 girl students were randomly selected for the post questionnaire interviews. The interview questions were focused on about what they mainly do between dinner time and bed time. The purpose of this interview was to find out why the bedtime does not differ much as the playing game time and sports time differ significantly.

The only girl goes to bed later than 1AM responded that she spent her most after school time mainly on playing mobile phone. 5 girl students responded they mainly spent on chatting and face to face friends visiting and outing. 4 girl students responded they spent their time alone in dorm reading novels or watching TV. The rest 9 girl students responded they spent their time either in the library or on some mics tasks. That indicate girl students are much less addicted to the virtual games than the boy students.

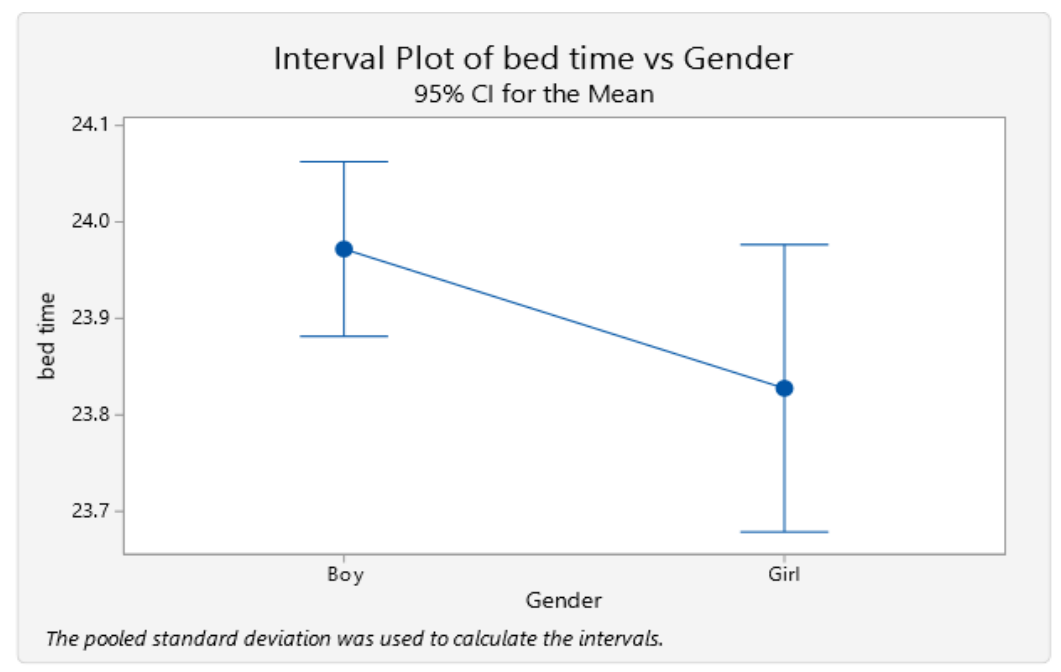

Figure 6. ANOVA test comparing the go to bed time between boy students and girl students

\section{Discussion and Conclusion}

It is obvious that, girl students are much better than boy students in English presentation performance in SUES, Like mentioned before, the dominating majors in this university are science and engineering, consequentially boy students are far more than the girl students. One of the major reasons to explain the lower scores of boy 
students is the lack of motive in participating in the courses and little efforts paid to develop their English presentation skills.

By analyzing the sample students' college life schedule and daily activities, video game playing and sports are the two major activities which cost most of the students' after school time. Boy students are clearly much more addicted to video game playing and sports. These two activities cause them more reluctant to actively participate in the English presentation courses. These courses require the interest to present clear ideas and communicate in the real person contacting occasions. In addition, the presentation soft skills and mastering various English expressing patterns are needed for a qualified presentation. Because playing video games and doing sports require neither real person contact nor presentation needs, boy students are getting used to the occasions with little or none language communications.

As comparing with the time that students spent on video game and sports, it is notable that the time boy students spent on the video game are far more than sports. It is obvious that the more video games they play, the more they are diverted away from the normal real person contact. Thus the low motives and interests in participating and learning English presentation skills are naturally resulted from. Though there are studies about playing video game helps to improve the English vocabulary(Nalliveettil, 2016), in this study about English presentation, the result turned to be opposite: the more time spent on video games, the fewer interests and motives students have towards English presentation courses It is common to see in the English presentation classroom, at least half of the boy students are playing mobile phones during the courses while few girl students do so by daily random observation.

From the data collected, it appears no evident differences in sleep time length and goes to bed time between boy students and girl students. It indicates that no matter playing video games or not, college students tend to sleep late, even the academic assignments are few. But the time they get engaged in after school activities differs much. Boy students are much more interested and indulged in video games and sports than girl students, which make them more reluctant to pay efforts in English presentation courses. Thus it explains to some extent why their performance in English presentation courses is much lower than girl students.

It is a malicious cycle that the boy students turn more to the video games and sports for fun, the fewer efforts they would give to English presentation course. Low attendance rate and high late rate occur often in boy students in SUES. In random classroom interviews, more than half of the boy students admit they are not interested in English presentation courses at all, they prefer to play games instead.

It is clear that playing video game effect students' interests and motives towards English presentation performance. Again, the strong motives are crucial in the English presentation. Though there is the gap between genders in learning English, the gap can be overcome easily by certain efforts paid. It is convinced in this study there are still quite a few boy students achieved as good as girl students in English presentation after they made certain but not big efforts.

There is another interesting finding in this study. During the random interview, girl students stated one of the factors they have the strong motive in English presentation course is the majority of the students are boy students. The gender distribution in the classroom is also a considerable factor in the future study.

This study discusses about the lifestyle elements in college life can dramatically influence the English presentation learning outcomes. There are still quite a few research works needed to do about the accuracy of the levels of these influences.

\section{References}

Aabid, A. (2013). Effects of different sleeping patterns on academic performance in medical school students. Natural Science, 5, 1193-1198. http://dx.doi.org/10.4236/ns.2013.511146

Azhaar, A. S., \& Rahma, A. (2012). The Influence of Gender on Omani College Students' English Language Learning Strategies, Comprehension and Motivation. International Journal of Applied Linguistics \& English Literature, 1(4).

Craton, J. (2011). The Effect of Videogames on Student Achievement, ACSD, Retrieved April 26, 2011, from http://www.acsd.org/article/the-effect-of-videogames-on-student-achievement

DeHann J., Reed, W. M., \& Kuwada, K. (2010). THE EFFECT OF INTERACTIVITY WITH A MUSIC VIDEO GAME ON SECOND LANGUAGE VOCABULARY RECALL. Language Learning \& Technology, 14(2), 74-94.

Fan, X. (2010). A Study of Gender Differences in English Learning Strategies of Middle School Students. The 
Conference on Web Based Business Management. Retrieved from http://file.scirp.org/pdf/18-1.1.1.pdf

JCSM. (2015). Recommended Amount of Sleep for a Healthy Adult: A Joint Consensus Statement of the American Academy of Sleep Medicine and Sleep Research Society. Journal of Clinical Sleep Medicine, $11(6)$.

Nalliveettil, G. M., \& Alenazi, T. H. K. (2016). The Impact of Mobile Phones on English Language Learning: Perceptions of EFL Undergraduates. Journal of Language Teaching and Research, 7(2). 264-272. https://doi.org/10.17507/jltr.0702.04

Shostya, A. (2015). The Use of Time among College Students $\backslash$ A U.S. - China Comparison. International Journal of Education, 7(1). https://doi.org/10.5296/ije.v7i1.7037

Wang, Q. (2015). A Study of the Influence of Gender Differences on English Learning of Senior High School Students. Higher Education of Social Science, 8(6), 66-69.

\section{Copyrights}

Copyright for this article is retained by the author(s), with first publication rights granted to the journal.

This is an open-access article distributed under the terms and conditions of the Creative Commons Attribution license (http://creativecommons.org/licenses/by/4.0/). 